\title{
Techno-functional Properties of Edible Packaging Films at Different Polysaccharide Blends
}

\author{
Abdul Khalil H. P. S., ${ }^{*}$ Suk Wy Yap, ${ }^{1}$ Owolabi F. A. T., ${ }^{1,2}$ Haafiz M. K. M., ${ }^{1}$ \\ Fazita M. R., ${ }^{1}$ Deepu A. Gopakumar, ${ }^{1}$ Hasan, M. ${ }^{3}$ and Samsul Rizal ${ }^{4}$ \\ ${ }^{1}$ School of Industrial Technology, Universiti Sains Malaysia, \\ 11800 USM Pulau Pinang, Malaysia \\ ${ }^{2}$ Division of Pulp and Paper, Federal Institute of Industrial Research Oshodi, \\ F.I.I.R.O. Rd, Lagos, Nigeria \\ ${ }^{3}$ Chemical Education Department, Universitas Syiah Kuala, Jln. Tgk. Daud Beureueh, \\ Darussalam, Banda Aceh, 23311 Indonesia \\ ${ }^{4}$ Department of Mechanical Engineering, Universitas Syiah Kuala, \\ Banda Aceh 23111, Indonesia \\ *Corresponding author: akhalilhps@gmail.com
}

Published online: 15 February 2019

To cite this article: Abdul Khalil, H. P. S. et al. (2019). Techno-functional properties of edible packaging films at different polysaccharide blends. J. Phys. Sci., 30(Supp. 1), 23-41, https://doi.org/10.21315/jps2019.30.s1.2

To link to this article: https://doi.org/10.21315/jps2019.30.s1.2

\begin{abstract}
Consequent to the recent global interest in biodegradable packaging in food and allied industries, this study investigated effect of blend ratio of the hybrid polysaccharide of corn starch and red seaweed on the properties of the developed film. The properties investigated include physical properties (thickness and water vapour permeability), mechanical properties (tensile strength, elongation and modulus) and optical properties while the complementary properties such as scanning electron microscope (SEM) and Fourier transform infrared (FTIR) spectroscopy were used to analyse possible chemical interactions within the films. Films manufactured with 100\% corn starch (CS) exhibited the lowest quality while the films developed from seaweed (SE) blend exhibited higher quality. Based on complementary analysis result, there was an excellent blend of the filler and the polysaccharide matrix. The overall film properties improved with the increase of the blend ratio. The results of the Young's modulus (YM) complemented the results obtained for the tensile strength (TS) and the percentage elongation (E). The solubility value of the composite films justifies them as good candidate for the food packaging applications.
\end{abstract}

Keywords: Biodegradable, polysaccharide, edible film, film opacity, hydrophobicity 


\section{INTRODUCTION}

Synthetic plastics are vastly utilised since the twentieth century as they can be easily processed at low cost to obtain the desired functional properties. However, the disposal of these materials has created negative impacts to the environment and this has caused consumers today to become more aware of the consequences. ${ }^{1}$ They have begun to focus on sustainability and supporting the efforts of biobased options in industrial development. Hence, composite materials derived from biodegradable polymers such as polysaccharides, proteins and lipids are highly sought after by the current research community due to their distinctive features compared with synthetic polymer materials, e.g., their nontoxicity, biodegradability and abundant availability. ${ }^{2}$

An individual polymer may show poor properties such as hydrophilicity, water solubility or weak mechanical strength. This can be effectively overcome by selecting an appropriate polymer to blend with in order to capitalise the maximum possible properties in the structure. ${ }^{3}$ Polymer blending is a useful technique which utilises low cost conventional technology to modify properties when needed. However, the aim of polymer blending is to increase the possible capacity of the performance of the material instead of altering the properties to a drastic level. ${ }^{4}$

As an alternative choice to replace the synthetic material, starch polymer plays an important role amongst the other biodegradable materials. It is widely utilised in both food and non-food applications such as edible packaging, adhesive, textile sizing and cosmetic products because it is easily obtainable, abundantly available, cheap, biodegradable and exhibits biocompatible features. ${ }^{5}$ Starch is essentially comprised of linear amylose and branched amylopectin. The relative amount of both of these macromolecular components in starch is dependent upon the source of the plant. It is known that cornstarch is composed of 30\% amylose and $70 \%$ amylopectin. The starch-based polymer, also known as thermoplastic starch (TPS), can be prepared by heating starch granules in the presence of a plasticiser, commonly water or glycerol. Although starch-based films are transparent, odourless and oxygen-impermeable, the fact that they are brittle and hydrophilic in nature has restricted their use in many applications. ${ }^{6}$ An effective way to overcome these drawbacks is by mixing the films with other natural polymers that have compatible interactions with starch. ${ }^{7}$

To fulfil the surging demand for natural and renewable materials, bio-based material from the marine environment especially seaweed, has received plenty attention recently. Seaweed could be a suitable candidate as a biopolymer as it is made up of bountiful polysaccharides, providing itself a large array of functional properties like good gelling ability, recyclability, thermal stability and effective against health 
risk. ${ }^{8}$ Alginate, agar and carrageenan are the most common polysaccharides derived from seaweed that have been utilised as film-forming materials. They have been explored extensively in several fields related to functional food, tissue engineering, drug delivery and textile sizing applications. ${ }^{9,10}$ However, the extraction process is not environmentally and economically friendly because it requires high amount of chemical and energy consumption. ${ }^{11}$ Moreover, it is believed that pure seaweed also contains other non-polysaccharide compounds that contribute to the film forming abilities of seaweed, including proteins and lipids. ${ }^{12}$ Kappaphycus alvarezii (K. alvarezii) is a type of red seaweed which is largely cultivated for the production of the hydrocolloid known as kappa-carrageenan ( $\kappa$-carrageenan). ${ }^{13}$ Previous studies have reported the feasibility of films developed from native $K$. alvarezii seaweed, with or without incorporated fillers, that have attained substantial mechanical strength and other functional properties that are required for several industrial applications. ${ }^{14-16}$

There has been a great interest to focus on binary mixtures of starch and seaweed derived polymers over the years, and significant improvement has been reported in the mechanical strength and other properties of the starch-based films. ${ }^{5,17,18}$ To the best of the authors' knowledge, a biopolymer composite film prepared from starch and native seaweed has not yet been explored. This study aims to provide knowledge on the effect of blend ratio on the properties of corn starch and red seaweed blend film.

\section{EXPERIMENTAL}

\subsection{Materials}

Corn starch (CS) of Bintang Brand was purchased from Thye Huat Chan Sdn. Bhd., Malaysia with moisture content of $10.11 \%$. Red seaweed (K. alvarezii) (SE) species was supplied by Green Leaf Synergy Sdn. Bhd., Tawau, Sabah. The dried seaweed was washed with running water to eliminate impurities and dirt. It was then soaked in distilled water for $3 \mathrm{~h}$ to be allowed to swell and soften. Later the softened seaweed was cut and chopped into pieces with a knife and dried in oven at $40^{\circ} \mathrm{C}$ for 3 days. Analytical grade glycerol (GLY) purchased from Ajax Chemicals, Sydney, Australia Pty. Ltd. was used without further analysis as plasticiser.

\subsection{Fabrication of Starch/Seaweed Blend Films}

Both solutions of $3 \%(\mathrm{wt} / \mathrm{vol}) \mathrm{SE}$ and $1 \%(\mathrm{wt} / \mathrm{vol}) \mathrm{CS}$ was mixed at different ratios as shown in Table 1 . Seaweed solutions were prepared by soaking the 
seaweed particles in distilled water overnight forming gelatinised seaweed. A 30\% (wt/wt) glycerol was added to the solution according to each film code. The blending ratio of the SE/CS samples is shown in Table 1.

Table 1: Composition and coding of starch and seaweed films.

\begin{tabular}{lccc}
\hline SE:CS ratio & SE $(\%$ vol $/$ vol $)$ & CS $(\%$ vol $/$ vol $)$ & GLY $(\%$ wt/total wt $)$ \\
\hline 100:0 (Blank SE) & 100 & 0 & 30 \\
$90: 10$ & 90 & 10 & 30 \\
$80: 20$ & 80 & 20 & 30 \\
$70: 30$ & 70 & 30 & 30 \\
$60: 40$ & 60 & 40 & 30 \\
$50: 50$ & 50 & 50 & 30 \\
$0: 100$ (Blank CS) & 0 & 100 & 30 \\
\hline
\end{tabular}

The composite film was prepared by blending the mixture of CS and SE solution at $250 \mathrm{rpm}$ for $20 \mathrm{~min}$ to ensure homogeneous dispersion. To ensure that the film forming solutions were completely solubilised, they were heated (below $90^{\circ} \mathrm{C}$ to prevent degradation) for $30 \mathrm{~min}$ with continuous agitation until clearer and diluted solutions were observed. They were later allowed to cool for $5 \mathrm{~min}$ and degassed under vacuum to remove bubbles trapped in solutions. After cooling, the film forming solutions were filtered using a $1.0 \mathrm{~mm}$ pore-size stainless steel sieve to further remove insoluble particles and bubbles. Then the filtered solution was cast on the Teflon-coated plates with dimensions $37 \mathrm{~cm} \times 25.5 \mathrm{~cm}$. They were oven-dried at $40^{\circ} \mathrm{C}$ for $24 \mathrm{~h}$. The dried films were then removed from the plates.

All of the freshly fabricated films were conditioned prior to subjecting them to further testing for mechanical and water vapour barrier properties in accordance with ASTM D618-61 (1993). All of the films were kept in sealed plastic bags and then stored in desiccators containing saturated sulfuric acid solution at $55 \% \pm 2 \%$ $\mathrm{RH}$ and $27^{\circ} \mathrm{C} \pm 2^{\circ} \mathrm{C}$ for 3 days.

\subsection{Characterisation of CS/SE Blend Films}

\subsubsection{Film thickness}

The manufactured films were cut into strips with the dimensions $2 \mathrm{~cm} \times 15 \mathrm{~cm}$. The film thickness was measured using a TMI Digital precision Micrometer model 49-86 with digital linear encoder measuring system and an ultra-clear, easy-toread digital display from TMI Trading Co. Ltd. (Shanghai, China), at five random locations on the film and the average was reported. 


\subsubsection{Tensile properties}

The tensile properties, i.e., tensile strength (TS), elongation (E) and Young's modulus (YM) were analysed using a Miniature Tensile Tester MT1175 (Diastron Instruments, United Kingdom) programmed with UvWin1000 software, in reference to ASTM D882-02 (Standard, 2002) conditioned at 58\% RH and $28^{\circ} \mathrm{C}$. Ten specimens with dimension $150 \mathrm{~mm} \times 10 \mathrm{~mm}$ were cut with a pen knife. The condition was set at $100 \mathrm{~mm}$ of initial grip separation and $50 \mathrm{~mm} \mathrm{~min}{ }^{-1}$ of crosshead speed.

\subsubsection{Water solubility}

The water solubility of the films was determined by the method described by Romero-Bastida et al., with slight modification. ${ }^{19}$ The films were cut into dimensions of $30 \mathrm{~mm} \times 30 \mathrm{~mm}$, weighed before immersing in distilled water agitated for $30 \mathrm{~min}$ at $200 \mathrm{rpm}$ and $25^{\circ} \mathrm{C} \pm 2{ }^{\circ} \mathrm{C}$ in an orbital shaker (Infors HT, Switzerland). The film solution was then filtered oven dried at $40^{\circ} \mathrm{C}$ for $24 \mathrm{~h}$ to obtain constant weight. The solubility of the blend films was calculated as the equation below:

$$
\text { Solubility }(\%)=\frac{\text { weight before immersion }- \text { weight after immersion }}{\text { weight before immersion }} \times 100 \%
$$

\subsubsection{Water vapour permeability}

The water vapour permeability (WVP) of the film samples was determined according to the techniques in ASTM E96-95 (1995) standard. ${ }^{20}$ Five specimens of each film formulations were cut into a size equal to the mouth diameter of the polypropylene circular cups. The cups were filled with $20 \mathrm{ml}$ of distilled water and the specimen sheets were attached and flatly sealed on top with vacuum grease. They were then weighed, and their initial reading was recorded before placed into a controlled chamber conditioned at $50 \% \pm 5 \% \mathrm{RH}$ and $25^{\circ} \mathrm{C} \pm 2{ }^{\circ} \mathrm{C}$. Weights of the cups were taken every hour for a total of $6 \mathrm{~h}$. The line graphs of weight changes against time were plotted and the slopes were calculated with regressions coefficient of $\geq 0.99$. The water vapour transmission rate (WVTR) $\left(\mathrm{g} \mathrm{m}^{-2} \mathrm{~h}^{-1}\right)$ and WVP $\left(\mathrm{g} \mathrm{Pa}^{-1} \mathrm{~s}^{-1} \mathrm{~m}^{-1}\right)$ of the films were calculated as following equations below:

$$
\begin{aligned}
\operatorname{WVTR}\left(\mathrm{g} \mathrm{m}^{-2} \mathrm{~h}^{-1}\right) & =\frac{\text { total weight of moisture loss }(\mathrm{g})}{\text { total time }(\text { day }) \times \text { exposed surface area }\left(\mathrm{m}^{2}\right)} \\
& =\frac{\text { slope of the graph }}{\text { exposed surface area }\left(\mathrm{m}^{2}\right)}
\end{aligned}
$$




$$
\operatorname{WVP}\left(\mathrm{g} \mathrm{Pa}^{-1} \mathrm{~s}^{-1} \mathrm{~m}^{-1}\right)=(\mathrm{WVTR} \times \mathrm{t}) / \mathrm{P}
$$

where $t$ is the thickness of film (m), WVTR is the water vapour transmission rate $\left(\mathrm{g} \mathrm{m}^{-2} \mathrm{~h}^{-1}\right)$, and $\mathrm{P}$ is the partial pressure difference of saturated water vapour across the films $(\mathrm{Pa})$.

\subsubsection{FTIR Spectroscopy}

The appearance and disappearance of functional groups occasioned by the possible chemical interactions during the film formations were monitored using Fourier transform infrared (FTIR) spectra which were recorded with infrared spectrometer (Spectrum 8900 IR Spectrometer, Shimadzu, Japan) using Attenuated Total Reflectance mode. Samples of dimensions $30 \mathrm{~mm} \times 30 \mathrm{~mm}$ were prepared. Spectral measurements were performed in the transmittance mode. Ten scans of each sample were obtained at the range of $400-4000 \mathrm{~cm}^{-1}$ wavelength.

\subsubsection{SEM}

The microstructural features of the surface of the films were examined using scanning electron microscopy (SEM) with model of EVO MA10 (Carl-Zeiss SMT, Oberkochen, Germany). Before the specimens were to be examined, they are bonded electrically to a SEM holder with double-sided carbon adhesive tape to minimise exposure to electron beams and avoid surface charge form on the specimens. The specimens were then sputter coated with a thin layer of goldpalladium by Polaron SC515 (Fiscons Instruments, United Kingdom). The images were taken at $100 \mathrm{X}$ and $500 \mathrm{X}$ magnifications controlled at accelerating $15 \mathrm{kV}$ voltage.

\subsubsection{Statistical Analysis}

IBM SPSS software, Windows version 22 (IBM, New York, United States) was used to analyse the data statistically from each test conducted in this work. The oneway analysis of variance (ANOVA) was applied to analyse the mean differences of all the data. Multiple comparisons of the differences in mean results of all samples were also evaluated using the Tukey's Test. 


\section{RESULTS AND DISCUSSION}

\subsection{Mechanical Properties}

The result of the mechanical properties for composite films with maize starch and red seaweed at different blend ratio in this study was in Table 2. From the result, the tensile properties were represented by TS, E and YM and the water properties represented by WVP.

Table 2: Mechanical and water barrier properties of the blend films.

\begin{tabular}{lcc}
\hline (SE:CS) & Thickness $(\mathrm{mm})$ & TS $(\mathrm{MPa})$ \\
Blend ratio & $0.1310 \pm 0.0025^{\mathrm{a}}$ & $72.86 \pm 1.52^{\mathrm{ab}}$ \\
\hline $100: 0(\mathrm{SE})$ & $0.1061 \pm 0.0034^{\mathrm{b}}$ & $77.00 \pm 2.10^{\mathrm{a}}$ \\
$90: 10$ & $0.1233 \pm 0.0063^{\mathrm{a}}$ & $76.70 \pm 3.54^{\mathrm{a}}$ \\
$80: 20$ & $0.0815 \pm 0.0011^{\mathrm{c}}$ & $66.81 \pm 3.73^{\mathrm{b}}$ \\
$70: 30$ & $0.0851 \pm 0.0009^{\mathrm{c}}$ & $59.82 \pm 3.26^{\mathrm{c}}$ \\
$60: 40$ & $0.0790 \pm 0.0053^{\mathrm{c}}$ & $58.01 \pm 2.37^{\mathrm{c}}$ \\
$50: 50$ & $0.0510 \pm 0.0014^{\mathrm{d}}$ & $14.66 \pm 1.81^{\mathrm{d}}$ \\
$0: 100(\mathrm{CS})$ & $\mathrm{YM}(\%)$ & $\mathrm{WVP}\left(\mathrm{g} \mathrm{Pa}{ }^{-1} \mathrm{~m}^{-1} \mathrm{~s}^{-1}\right)$ \\
\hline SE:CS) & $4.63 \pm 0.59 \mathrm{~b}$ & $3.85 \mathrm{E}-10 \pm 0.08 \mathrm{a}$ \\
Blend ratio & $4.60 \pm 0.29 \mathrm{~b}$ & $3.12 \mathrm{E}-10 \pm 0.10 \mathrm{~b}$ \\
\hline $100: 0(\mathrm{SE})$ & $4.31 \pm 0.45 \mathrm{~b}$ & $3.63 \mathrm{E}-10 \pm 0.09 \mathrm{a}$ \\
$90: 10$ & $4.05 \pm 0.35 \mathrm{~b}$ & $2.40 \mathrm{E}-10 \pm 0.03 \mathrm{c}$ \\
$80: 20$ & $4.16 \pm 0.60 \mathrm{~b}$ & $1.67 \mathrm{E}-10 \pm 0.06 \mathrm{~d}$ \\
$70: 30$ & $3.02 \pm 0.08 \mathrm{~b}$ & $2.32 \mathrm{E}-10 \pm 0.12 \mathrm{c}$ \\
$60: 40$ & $14.20 \pm 0.69 \mathrm{a}$ & $1.00 \mathrm{E}-10 \pm 0.05 \mathrm{e}$ \\
\hline $50: 50$ &
\end{tabular}

Note: a-f represent significantly different values $(p<0.5)$ analysed by Tukey's Test

Comparing the control films, CS had weaker TS (14.66 MPa) than the SE which was $72.86 \mathrm{MPa}$. This can be due to the existence of linear sulphated polysaccharides in SE especially the $\kappa$-carrageenan which consists of alternating chains of D-galactose-sulphate and 3,6-anhydrogalcatose, and owns only one negative charge per unit of disaccharide. Therefore, it is inclined to form strong and rigid gel. $^{18,21,22}$ It was also observed that the TS of the composite films increased with the seaweed/starch blend ratio from 50:50 to 90:10 (SE: CS). This also indicated the improvement of TS of the films with the increase of SE content in the films. This is attributable to the interactions and compatibility of the CS and SE in the matrix. Similarly, the improvement of TS of the composite films was attributed to 
higher -OH content of SE which promoted more double helix associations of SE to exist in the film matrix, hence this allowed more rigid network to be formed and therefore resulted in composite films with stronger TS. ${ }^{23}$

Moreover, as both CS and SE are hydrophilic in nature, this could promote good interactions between CS and SE resulting in good compatibility between them in the matrix formed. This could be associated with the chain pairing reaction between CS and SE. Similar explanation has also been previously reported. ${ }^{8}$ As the $\kappa$-carrageenan, the main polysaccharide components existed in the SE species used in this study, owns a net negative charge, this allowed it to be sensitive to the electrostatic interactions with other polymers by pairing with the positively charged groups, e.g., starch endogenous protein. ${ }^{24-26}$ The observed improvement in TS of the manufactured films was similar to a number of findings in the literature. ${ }^{7,13,18,23}$

The percentage $\mathrm{E}$ of the composite films with the effect of blend ratio is shown in Table 2. The elongation $\mathrm{E}$ of the blend ratio ranged from $5.43 \%$ to $19.23 \%$. Comparing the control films, pure starch film (CS) with 5.43\% had weaker E than the pure seaweed film (SE) with $15.87 \%$. Among the films in this stage, composite film with 50:50 (SE:CS) blend ratio exhibited the highest E, which was 19.23\%. Although the increment of SE:CS blend ratio did not show a clear pattern on the E results, however, the addition of SE into CS showed higher E results than the control CS film, indicating the improvement in flexibility of the films. This can be related to the hygroscopic nature of SE which promotes plasticising effect in the matrix. $^{18}$

The behaviours of TS and $\mathrm{E}$ of the composite films with the blend ratio effect could also be verified with the YM values in Table 2. YM is a parameter that defines the tendency to deform by forces. It is known that a more flexible material has a lower YM, indicating that the material has higher ability to be deformed with less force. ${ }^{22}$ The YM values of this stage ranged from 3.02 MPa to $14.20 \mathrm{MPa}$. Although the effect of blend ratio has no effect on the YM results of the composite films, the YM result of the control CS film which was $14.20 \mathrm{MPa}$ was relatively higher than the films containing SE that were within $3.02 \mathrm{MPa}$ to $4.63 \mathrm{MPa}$, regardless of the variation of blend ratio. This indicated that the incorporation of SE into CS had improved the flexibility of the films. A similar phenomenon was also reported in other composite systems, in which the incorporation of a seaweed-derived polymer (e.g., carrageenan) improved the flexibility of polyvinyl alcohol-based film. ${ }^{27}$

The WVP results of the composite films with different blend ratios (Table 2) shows that the control CS film gives the least WVP which was $1.00 \times 10^{-10} \mathrm{~g} \mathrm{~Pa}^{-1} \mathrm{~m}^{-1} \mathrm{~s}^{-1}$ among the other films, whereas the control SE film showed the highest WVP which was $3.86 \times 10^{-10} \mathrm{~g} \mathrm{~Pa}^{-1} \mathrm{~m}^{-1} \mathrm{~s}^{-1}$. The trend of the 
WVP results of the composite films with the increment of SE:CS blend overall increased with the thickness of films as the total concentration of both CS and SE components increased due to the enrichment of free hydroxyl groups from both CS and SE enhanced the interactions with the water molecules. Thus, this promoted higher permeation rate of water across the film membrane.

However, regardless of the control films (CS and SE), the composite film with $60: 40$ blend ratio showed lowest WVP result which was $1.67 \times 10^{-4} \mathrm{~g}^{-1} \mathrm{kPa}^{-1} \mathrm{~s}^{-1}$ among the other composite films in this stage. The difference in WVP results with the effect of blend ratio could be due to the difference in interactions within the matrix components. ${ }^{8}$ When strong interactions occurred within the CS and SE components, a compact structure of matrix was formed, and this could reduce the free volume in matrix and also inhibited the intermolecular and hydrophilic interaction of water occurring in the film. ${ }^{7}$

\subsection{Film Solubility}

The water solubility of the composite films developed from CS/SE blend ratio were shown in Figure 1. Water solubility test is a measurement of film's resistance to water and it is closely related to hydrophilicity of a material. ${ }^{28}$ It is an important parameter especially in packaging application where high water activity or high moisture contact can occur in the film coating for food. ${ }^{29}$ Insoluble film is functional to situation whereby solubility can be controlled in order to prevent food from moisture loss. ${ }^{30}$ Films with higher water solubility mostly have lower water resistance. However, this feature may be a merit to situation where the material is needed to melt upon consumption or to be used as biodegradable packaging material. $^{29}$

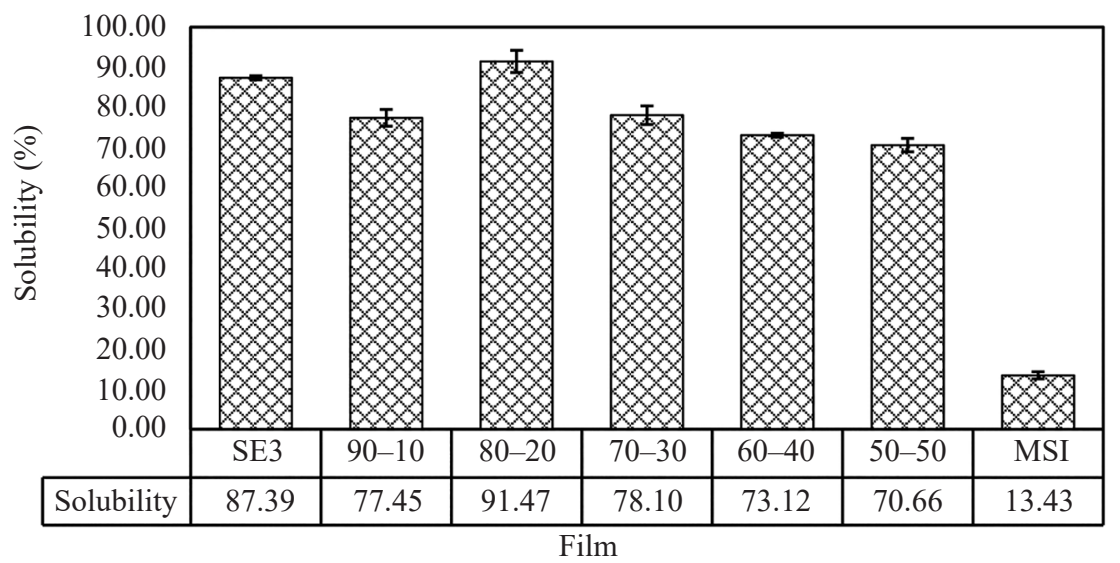

Figure 1: Water solubility results of the composite films with the effect of blend ratio. 
From the result, CS exhibited relatively lower water absorption value which was $13.43 \%$ than the SE film. The moisture content of the composite films generally increased with the increment of SE:CS blend ratio up to 80:20. These results were attributed to the polyelectrolyte nature of SE which contains hydrophilic sulphate esters and cations that were involved in the structural changes of SE helices to coil conformation when in excess water. ${ }^{31}$ Meanwhile, the water solubility of composite film at 90:10 (SE:CS) blend ratio fluctuated to a lower value of $77.45 \%$. It can be associated with the interaction mechanism that the formation of cross-linking between the chains of SE polysaccharides and addition of low amount of CS into the matrix has acted as filler to further strengthening the network. This could reduce the availability of free hydroxyl groups in composite films to have the hydrophilic interactions in excess water. ${ }^{32}$ The solubility values of the composite films were in the range of $70.66 \%$ to $77.45 \%$, which were good merits for the packaging applications. As the water solubility of the composite films exhibited higher results than the pure starch, this indicated that they had better rate of decomposition. ${ }^{23}$

\subsection{Film Opacity}

Protection against the light deterioration is also an important aspect in film packaging applications. Figure 2 presented the opacity results of the maize starch and red seaweed films with the effect of blend ratio. The opacity results of the films with the effect of blend ratio in this stage ranged from 14.73 to 16.00. Among the control films, the SE film with 16.00 exhibited higher opacity result than CS with 14.73 , indicating that the pure SE film was able to block more light transmitted across the film than CS. It was noticeable in general that the opacity results significantly increased with the increment of SE:CS blend ratio. This also can be related to the SE component contains light-absorbing pigment namely carotenoid which inhibited the light rays from penetrating across the film. ${ }^{33}$ The opacity results of the films in this study are in line with study reported by Larotonda which stated the increase of carrageenan content decreased the transparency of the starchcarrageenan films, as the low transparency implies that it has high opacity. ${ }^{34}$

\subsection{Spectra Analysis}

FTIR spectroscopy was used to monitor changes of chemical groups such as shifting of peak intensity and absorption band. ${ }^{35}$ In composite films, compatibility is assured when the presence of molecular interactions is detected in the FTIR analysis. ${ }^{20}$ The IR spectra of the control films and composite films are shown in Figure 3. As shown in Figure 4, the region within the $3100 \mathrm{~cm}^{-1}$ to $3500 \mathrm{~cm}^{-1}$ absorption band represented the stretching vibration of the hydroxyl group. In addition, spectral bands within $2800-3000 \mathrm{~cm}^{-1}$ denoted the $-\mathrm{CH}$ stretching 
region in the composite film. ${ }^{36}$ The region ranged between $700-1400 \mathrm{~cm}^{-1}$ correspond the functional groups of carbohydrates in the polysaccharide components which exist in the films. ${ }^{32}$ The distribution of these absorption bands are in conformity with the results reported previously including the $\kappa$-carrageenan/ locust bean gum films, l-carrageenan/rice starch films, carrageenan/sago starch and also the galactomannan films..$^{8,9,32,36}$

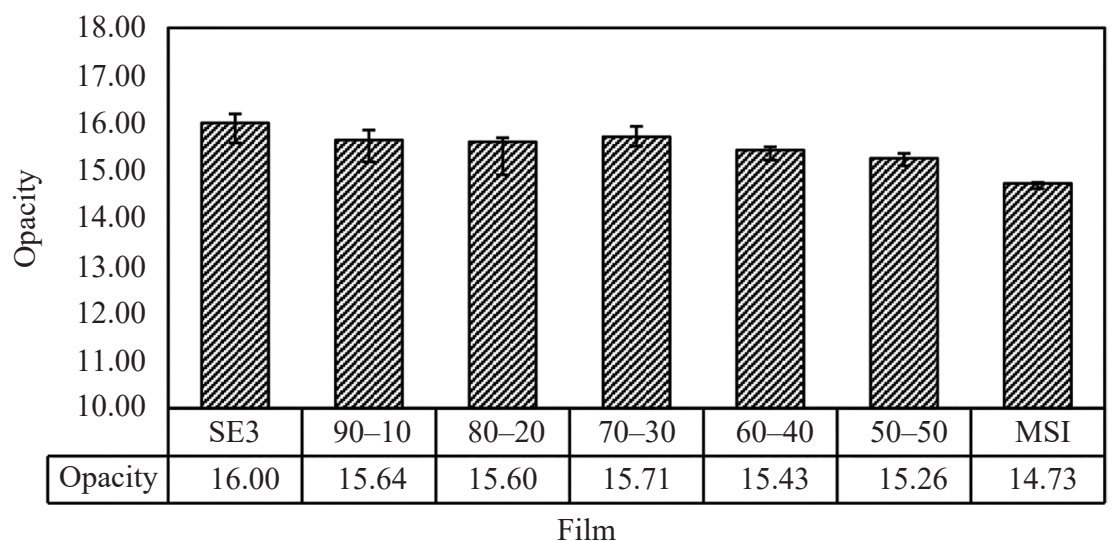

Figure 2: Opacity results of the composite films with the effect of blend ratio.

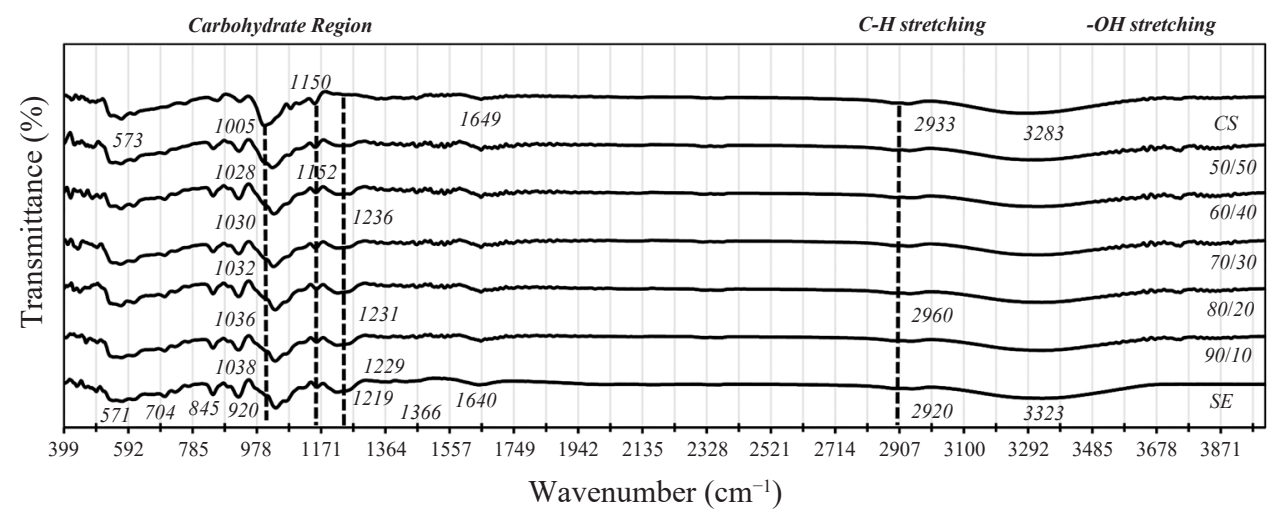

Figure 3: IR spectra of the control films and the composite films varying with different $\mathrm{SE}$ :CS blend ratios. 

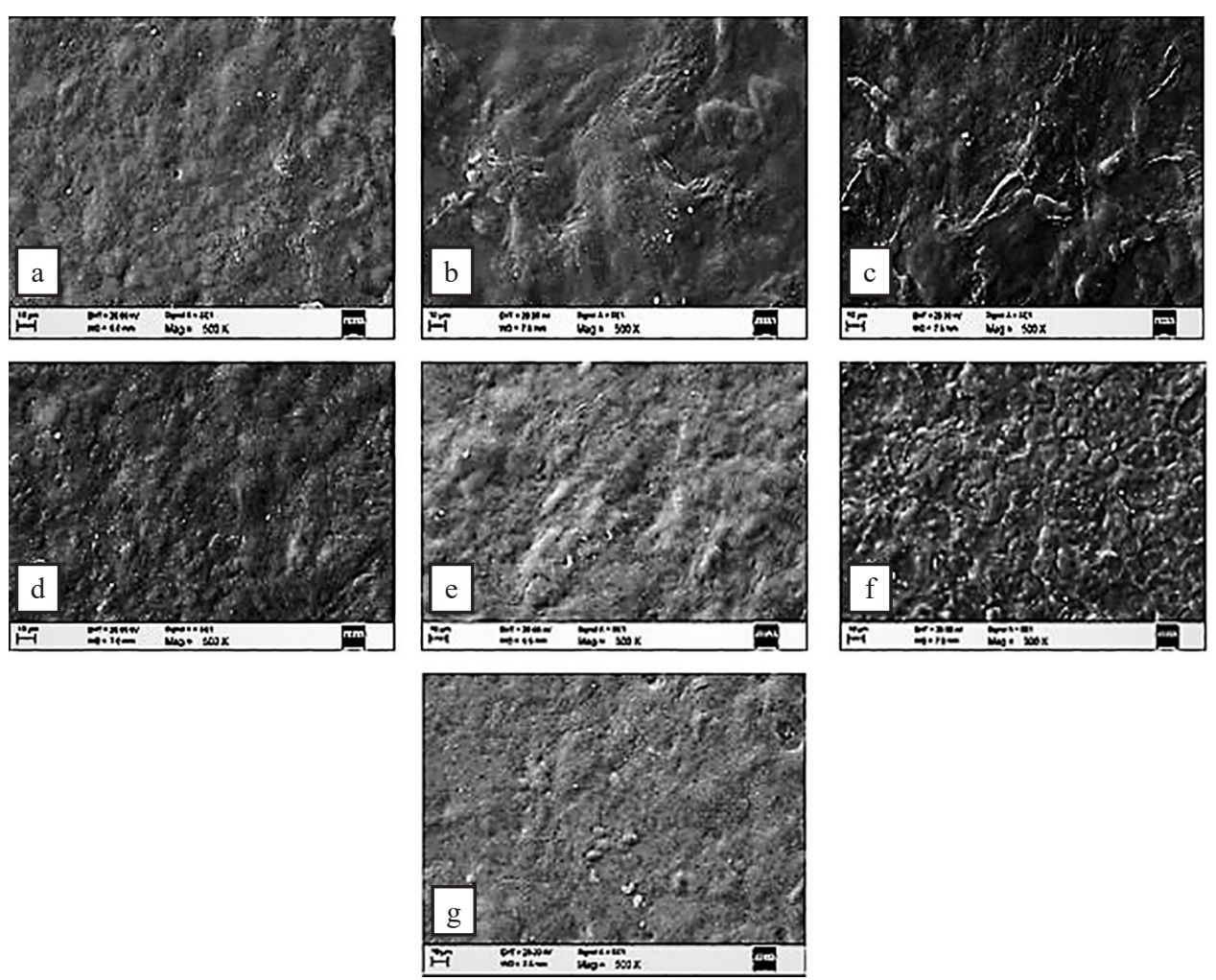

Figure 4: Micrographs of all the films at red seaweed:maize starch blend ratio at (a) seaweed (control), (b) 90:10, (c) 80:20, (d) 70:30, (e) 60:40, (f) 50:50 and (g) corn starch. Observed at 500X magnification.

The characteristic bands of the starch and seaweed identified from the spectra analysis of the control films (CS and SE film, respectively) were as shown in Tables 3 and 4. As highlighted in Figure 3 and Table 3, the pure seaweed film SE showed its main absorption bands at $1219 \mathrm{~cm}^{-1}, 920 \mathrm{~cm}^{-1}$ and $845 \mathrm{~cm}^{-1}$ that correspond to the $\mathrm{S}=\mathrm{O}$ bond of the sulphate ester, $\mathrm{C}=\mathrm{O}$ and $\mathrm{C}-\mathrm{C}$ bond vibrations of 3,6-anhydrogalactose, and also the stretching of D-galactose-4-sulfate, respectively. ${ }^{37,38}$ As mentioned in the literature, the difference in the content of these sulphated polysaccharides compounds in SE component affects the properties of seaweed in terms of gelling ability, solubility, melting temperature, setting and texture. ${ }^{7,39}$ Thus, it can be deduced that varying the seaweed concentration in this study obliquely affected the properties of the composite films, as the content of the polysaccharide compounds that exist in seaweed component also differed. 
Table 3: Characteristic bands of the seaweed component identified through the spectral analysis of the control SE.

\begin{tabular}{ll}
\hline & \multicolumn{1}{c}{$\mathrm{SE}$} \\
\hline Wavenumber $\left(\mathrm{cm}^{-1}\right)$ & Groups \\
\hline 422 and 600 & Chlorophyll a, carotenoid, and phaeophytin pigments stretching \\
571 & Phosphate groups stretching \\
700 & $\mathrm{~N}-\mathrm{H}$ group bending \\
845 & $-\mathrm{O}-\mathrm{SO}_{3}$ of D-galactose-4 sulphated \\
920 & $\mathrm{C}-\mathrm{O}-\mathrm{C}$ vibration of 3,6- anyhydro-galactose \\
1038 & $\mathrm{C}-\mathrm{O}$ and $\mathrm{C}-\mathrm{C}$ stretching of pyranose ring \\
1219 & $\mathrm{~S}=\mathrm{O}$ bond stretching of sulphate ester groups \\
1366 and 1640 & Carbonyl groups stretching \\
2920 & Free methyl groups stretching \\
3323 & Free $\mathrm{OH}, \mathrm{SO}_{2}$ and NH groups stretching vibration \\
\hline
\end{tabular}

Table 4: Characteristic bands of the starch component identified through the spectral analysis of the control CS.

\begin{tabular}{ll}
\hline & \multicolumn{1}{c}{ CS } \\
\hline Wavenumber $\left(\mathrm{cm}^{-1}\right)$ & Groups \\
\hline $573,760,858$ and 928 & Anhydroglucose ring stretching vibration \\
999,1078 and 1150 & C-O bond stretching \\
1649 & Water \\
2933 & C-H bond stretching \\
3283 & Free, inter, or intramolecular -OH groups stretching vibration \\
\hline
\end{tabular}

The spectral analysis of the CS film also displayed the presence of pigments existing in seaweed component that gives it the yellowish colour which the wavelength ranged between $422 \mathrm{~cm}^{-1}$ and $600 \mathrm{~cm}^{-1} .{ }^{40}$ This observation also verified the obtained and discussed optical properties' results of both stages in this study.

Other main absorption peaks of seaweed component observed at the spectral analysis of the control seaweed film SE included the methyl group stretching at $2940 \mathrm{~cm}^{-1}$, carbonyl groups stretching at wavenumbers $1366 \mathrm{~cm}^{-1}$ and $1640 \mathrm{~cm}^{-1}$, and glycosidic linkage which joined the galactan units of seaweed stretching at $1034 \mathrm{~cm}^{-1}$. In addition, the protein components that exist in seaweed can also be detected by the spectral analysis including the bending of N-H group located at $700 \mathrm{~cm}^{-1}$, and also $571 \mathrm{~cm}^{-1}$ corresponding to the stretching of the phosphate group in seaweed component. ${ }^{41}$ Wavenumbers at $1078 \mathrm{~cm}^{-1}, 1150 \mathrm{~cm}^{-1}$ and $1005 \mathrm{~cm}^{-1}$ 
corresponded to the $\mathrm{C}=\mathrm{O}$ bond stretching; anhydroglucose ring stretching vibration at $573 \mathrm{~cm}^{-1}, 760 \mathrm{~cm}^{-1}, 858 \mathrm{~cm}^{-1}$ and $928 \mathrm{~cm}^{-1}$, also at $1649 \mathrm{~cm}^{-1}$ attributed to the water molecules presented in starch; stretching of $\mathrm{C}-\mathrm{H}$ bond corresponded at $2933 \mathrm{~cm}^{-1}$; and lastly a broad brand vibration at $3283 \mathrm{~cm}^{-1}$ due to the stretching of free, intermolecular, or intramolecular -OH groups in starch..$^{42,43}$

As mentioned, the molecular interactions occur within the maize starch and red seaweed in the composite films can be identified through spectral analysis by observing the shifting of absorption peaks and decrement in the peak intensities in respective to their characteristic groups. ${ }^{32}$ It can be observed through Figure 3 that the decrement of starch's characteristic band intensities in the composite films at $573 \mathrm{~cm}^{-1}$ and $1150 \mathrm{~cm}^{-1}$ wavenumbers with the increase of SE:CS blend ratio. At the same time, the peak intensity of the seaweed's characteristic groups in the composite films at $845 \mathrm{~cm}^{-1}, 922 \mathrm{~cm}^{-1}, 1038 \mathrm{~cm}^{-1}$ and $1219 \mathrm{~cm}^{-1}$ wavenumbers also decreased with the decrement of SE:CS blend ratio (Figure 3).

On the other hand, the shifting of the absorption bands of the characteristic groups with the effect of blend ratio in maize starch and red seaweed films can be observed (Figure 3) in which the $-\mathrm{C}-\mathrm{O}$ bond and $\mathrm{C}-\mathrm{C}$ bond of the glycosidic linkages at $1038 \mathrm{~cm}^{-1}$ (SE) shifted to $1028 \mathrm{~cm}^{-1}$ (50:50) and the $\mathrm{C}-\mathrm{O}$ bond stretching at $1150 \mathrm{~cm}^{-1}$ (CS) shifted to $1152 \mathrm{~cm}^{-1}$ (50:50). The shifting of $\mathrm{CO}$ - absorption peak in both SE and CS could relate to the interactions among themselves. Similar observation was also shown in the $\kappa$-carrageenan/locust bean gum film. ${ }^{32}$ In addition, other shifted peaks also can be observed at: $1219 \mathrm{~cm}^{-1}$ (SE) to $1236 \mathrm{~cm}^{-1}(60: 40)$ corresponded to the $\mathrm{S}=\mathrm{O}$ bond of sulphate ester groups and also at $2933 \mathrm{~cm}^{-1}$ (CS) to $2960 \mathrm{~cm}^{-1}$ (80:20) associated with the stretching of methyl groups, could be due to the physical entanglements between the two materials involved with hydrogen bonding., ${ }^{8,23,32}$ The pattern of shifting of the absorption peaks involving both the components simultaneously showed that there are molecular interactions happening within the two components in the composite films with the effect of SE:CS blend ratio. This also obliquely implies that the components are mutually compatible. ${ }^{32}$ The observations were also in conformity with other studies including $\kappa$-carrageenan/thermoplastic starch film and also $\kappa$-carrageenan/ locust bean gum film..$^{23,32}$

\subsection{SEM}

The surface morphology of the films of maize starch and red seaweed in different blend ratio was observed by SEM analysis and the micrographs of the film surface are displayed in Figure 4. 
It can be observed in the micrographs that there were slight difference in surface structure between the composite films (with different SE:CS blend ratios) and the control films (SE and CS). Regardless of the SE:CS blend ratio, the composite films exhibited rougher and denser surface with the presences of wrinkles and aggregates in comparison to the control films. This might be due to the embedment of the starch particles into the seaweed matrix. Similar observation also discussed by previous works, observed that during the nanocellulose particles agglomerated in agar matrix when the agar concentration was high in the composition. ${ }^{44}$ However, although the composite films appeared rougher and denser, it can be observed that these irregularities distributed uniformly throughout the surface of the matrices, implying that there is good homogeneity in the composite films' structure.

Overall, it also can be said that all the films formed by maize starch and red seaweed showed uniform distributed and compact surface structure without any cracks. This can be explained by that the components in the matrix are good adhesion and thus led to a good homogeneity in film surface. ${ }^{13}$ Besides that, the good homogeneity of films' surface could also relate to the processing of film preparation when all the components including starch, seaweed and glycerol were subjected to even stirring and heat before the film fabrication step, and thus a stable mixture can form a uniform structure of film. Previous studies also showed and discussed about the significance of continuous heat and stirring application during the film preparation and thus affecting the homogeneity of the starch and extracted seaweed films. ${ }^{13,45}$

Moreover, it can also be observed that there were no phase separations that can be detected in the composite films with different blend ratios. This indicated that there was a good compatibility between the components in the matrix of the composite films. This observation also supported the discussion on the film properties in the previous subsections that there were good molecular interactions between maize starch and red seaweed in the matrix, and thus led to a good compatibility between the components. ${ }^{45}$

\section{CONCLUSION}

The composite films from red seaweed and corn starch blend plasticised with glycerol were successfully developed by simple solvent casting method. The overall results of the evaluation on the films' properties in this study showed blend ratio of corn starch and red seaweed have different strength of molecular interaction within themselves, and in turn, affecting the properties of the obtained composite films differently. Composite films with higher seaweed content were observed to have improved mechanical properties, water absorption, water solubility and opacity. 
Besides that, the water vapour permeability of the composite films increased linearly with the increase in content of both starch and seaweed. In particular, the composite film with 80:20 (red seaweed:corn starch) blend ratio exhibited the highest tensile strength and the composite film with 60:40 (red seaweed:corn starch) blend ratio exhibited the best water barrier and the highest thermal stability result among the other composite films. Spectral analysis by FTIR revealed the molecular interactions occurred within corn starch and red seaweed in the matrix and this also proved the good miscibility of the two components in the matrix of the composite films. Morphological analysis showed that all the films fabricated by corn starch and red seaweed had homogeneous, compact and uniform structure, indicating that the components in the film matrix are compatible. Based on the results, different film composition can be tailored and optimised according to the results obtained in order to achieve desired properties and functionality required for certain application.

\section{ACKNOWLEDGEMENTS}

The authors gratefully acknowledge the Ministry of Higher Education for the Fundamental Research Grant Scheme-Malaysia's Rising Star Award 2015 (FRGS203/PTEKIND/6711531).

\section{REFERENCES}

1. Rhim, J. W. \& Wang, L. F. (2014). Preparation and characterization of carrageenanbased nanocomposite films reinforced with clay mineral and silver nanoparticles. Appl. Clay Sci., 97, 174-181, https://doi.org/10.1016/j.clay.2014.05.025.

2. Vieira, M. G. A. et al. (2011). Natural-based plasticizers and biopolymer films: A review. Eur. Polym. J., 47(3), 254-263, https://doi.org/10.1016/j.eurpolymj. 2010.12.011.

3. Abdul Khalil, H. A. et al. (2018). Microbial-induced CaCO3 filled seaweedbased film for green plasticulture application. J. Clean. Prod., 199, 150-163, https://doi.org/10.1016/j.jclepro.2018.07.111.

4. Abdul Khalil, H. P. S. et al. (2018). Development and characterization of bamboo fiber reinforced biopolymer films. Mater. Res. Exp., 5(8), 085309, https://doi.org/ 10.1088/2053-1591/aad2a0.

5. Lafargue, D., Lourdin, D. \& Doublier, J. L. (2007). Film-forming properties of a modified starch/К-carrageenan mixture in relation to its rheological behaviour. Carb. Polym., 70(1), 101-111, https://doi.org/10.1016/j.carbpol.2007.03.019.

6. Rizal, S. et al. (2018). Enhancement of the physical, mechanical, and thermal properties of epoxy-based bamboo nanofiber nanocomposites. Biores., 13(4), 7709-7725. 
7. Poeloengasih, C. D. et al. (2017). Potential of sago starch/carrageenan mixture as gelatin alternative for hard capsule material. AIP Conf. Proceed., 1823(1), 020035, https://doi.org/10.1063/1.4978108.

8. Thakur, R. et al. (2016). Characterization of rice starch-1-carrageenan biodegradable edible film: Effect of stearic acid on the film properties. Int. J. Biol. Macromol., 93, 952-960, https://doi.org/10.1016/j.ijbiomac.2016.09.053.

9. Gade, R. et al. (2013). Seaweeds: A novel biomaterial. Int. J. Pharm. Pharm. Sci, 5(2), 0975-1491.

10. Rosamah, E. et al. (2018). The role of bamboo nanoparticles in kenaf fiber reinforced unsaturated polyester composites. J. Renew. Mater., 6(1), 75-86, https://doi.org/10.7569/JRM.2017.634152.

11. Abdul Khalil, H. P. S. et al. (2017). Biodegradable polymer films from seaweed polysaccharides: A review on cellulose as a reinforcement material. Exp. Polym. Lett., 11(4), 244-265, https://doi.org/10.3144/expresspolymlett.2017.26.

12. Suraya, N. L. M. et al. (2018). Synergistic effect of oil palm based pozzolanic materials/oil palm waste on polyester hybrid composite. J. Polym. Environ., 1-10, https://doi.org/10.1007/s10924-018-1278-4.

13. Jumaidin, R. et al. (2017). Effect of seaweed on mechanical, thermal, and biodegradation properties of thermoplastic sugar palm starch/agar composites. Int. J. Biol. Macromol., 99, 265-273, https://doi.org/10.1016/j.ijbiomac.2017. 02.092 .

14. Siah, W. M., Aminah, A. \& Ishak, A. (2015). Edible films from seaweed (Kappaphycus alvarezii). Int. Food Res. J., 22(6), 2230-2236.

15. Abdul Khalil, H. P. S. et al. (2016). Cellulosic pulp fiber as reinforcement materials in seaweed-based film. Biores., 12(1), 29-42, https://doi.org/10.15376/ biores.12.1.29-42.

16. Abdul Khalil, H. P. S. et al. (2017). Oil palm shell nanofiller in seaweed-based composite film: Mechanical, physical, and morphological properties. Biores., 12(3), 5996-6010, https://doi.org/10.15376/biores.12.3.5996-6010.

17. Wang, L. et al. (2011). Preparation process of corn starches/sodium alginate blend edible films. Paper presented at the Remote Sensing, Environment and Transportation Engineering (RSETE) International Conference, Nanjing, 70037005.

18. Abdou, E. \& Sorour, M. (2014). Preparation and characterization of starch/ carrageenan edible films. Int. Food Res. J., 21(1), 189-193.

19. Romero-Bastida, C. A. et al. (2005). Physicochemical and microstructural characterization of films prepared by thermal and cold gelatinization from nonconventional sources of starches. Carbohydr. Polym., 60(2), 235-244, https://doi. org/10.1016/j.carbpol.2005.01.004.

20. Xu, Y. X. et al. (2005). Chitosan-starch composite film: Preparation and characterization. Ind. Crops Prod., 21(2), 185-192, https://doi.org/10.1016/j. indcrop.2004.03.002.

21. Park, S. Y. et al. (2001). Biopolymer composite films based on $\kappa$-carrageenan and chitosan. Mater. Res. Bull., 36(3-4), 511-519, https://doi.org/10.1016/S00255408(01)00545-1. 
22. Briones, A. V. et al. (2004). Tensile and tear strength of carrageenan film from Philippine Eucheuma species. Mar. Biotechnol., 6(2), 148-151, https://doi.org/ 10.1007/s10126-003-0005-9.

23. Flores, A. C., Punzalan, E. R. \& Ambangan, N. G. (2015). Effects of kappacarrageenan on the physico-chemical properties of thermoplastic starch. Kimika, 26, 11-17, https://doi.org/10.26534/kimika.v26i1.10-16.

24. Tecante, A. \& Santiago, M. D. C. N. (2012). Solution properties of $\kappa$-carrageenan and its interaction with other polysaccharides in aqueous media. In (Ed.) De Vicente, J. Rheology, Rijeka: InTech, https://doi.org/10.5772/36619.

25. Cunha, L. \& Grenha, A. (2016). Sulfated seaweed polysaccharides as multifunctional materials in drug delivery applications. Mar. Drugs, 14(3), https://doi.org/10.3390/md14030042.

26. Lascombes, C. et al. (2017). Starch-carrageenan interactions in aqueous media: Role of each polysaccharide chemical and macromolecular characteristics. Food Hydrocoll., 66, 176-189, https://doi.org/10.1016/j.foodhyd.2016.11.025.

27. Kanatt, S. R. et al. (2015). K. alvarezii: Its antioxidant potential and use in bioactive packaging films. J. Microb. Biotechnol. Food Sci., 5(1), 1-6, https://doi. org/10.15414/jmbfs.2015.5.1.1-6.

28. Wang, L. et al. (2013). Preparation and characterization of active films based on chitosan incorporated tea polyphenols. Food Hydrocoll., 32(1), 35-41, https://doi.org/10.1016/j.foodhyd.2012.11.034.

29. Bourtoom, T. \& Chinnan, M. S. (2008). Preparation and properties of rice starchchitosan blend biodegradable film. LWT-Food Sci. Technol., 41(9), 1633-1641, https://doi.org/10.1016/j.lwt.2007.10.014.

30. Aprilia, N. S. et al. (2018). Role of dispersion time on the properties of enzymatictreated bamboo cellulose nanofibers. Mater. Res. Exp., 5(10), https://doi.org/ 10.1088/2053-1591/aadaca.

31. Tavassoli-Kafrani, E., Shekarchizadeh, H. \& Masoudpour-Behabadi, M. (2016). Development of edible films and coatings from alginates and carrageenans. Carbohydr. Polym., 137, 360-374, https://doi.org/10.1016/j.carbpol.2015.10.074.

32. Martins, J. T. et al. (2012). Synergistic effects between $\kappa$-carrageenan and locust bean gum on physicochemical properties of edible films made thereof. Food Hydrocoll., 29(2), 280-289, https://doi.org/10.1016/j.foodhyd.2012.03.004.

33. Stahl, W. \& Sies, H. (2012). $\beta$-Carotene and other carotenoids in protection from sunlight. Am. J. Clin. Nutr., 96(5), 1179S-1184S, https://doi.org/10.3945/ajcn. 112.034819 .

34. Larotonda, F. D. S. (2007). Biodegradable films and coatings obtained from carrageenan from Mastocarpus stellatus and starch from Quercus suber. PhD diss., University of Porto.

35. Wanchoo, R. K. \& Sharma, P. K. (2003). Viscometric study on the compatibility of some water-soluble polymer-polymer mixtures. Eur. Polym. J., 39(7), 14811490, https://doi.org/10.1016/S0014-3057(02)00386-5.

36. Cerqueira, M. A. et al. (2011). Structural and thermal characterization of galactomannans from non-conventional sources. Carbohydr. Polym., 83(1), 179185, https://doi.org/10.1016/j.carbpol.2010.07.036. 
37. Paridah, M. T. et al. (2018). Alkaline sulfite anthraquinone and methanol (ASAM) pulping process of tropical bamboo (Gigantochloa scortechinii). Rijeka: InTech, https://doi.org/10.5772/intechopen.76806.

38. Dungani, R. et al. (2017). Preparation and fundamental characterization of cellulose nanocrystal from oil palm fronds biomass. J. Polym. Environ., 25(3), 692-700, https://doi.org/10.1007/s10924-016-0854-8.

39. Pereira, L., Gheda, S. F. \& Ribeiro-Claro, P. J. (2013). Analysis by vibrational spectroscopy of seaweed polysaccharides with potential use in food, pharmaceutical, and cosmetic industries. Int. J. Carbohydr. Chem., Article ID 537202, https://doi.org/10.1155/2013/537202.

40. Abdul Khalil, H. P. S. et al. 2017. Biodegradable polymer films from seaweed polysaccharides: A review on cellulose as a reinforcement material. Exp. Polym. Lett., 11(4), 244-265, https://doi.org/10.3144/expresspolymlett.2017.26.

41. Kumar, K. S., Ganesan, K. \& Rao, P. S. (2015). Seasonal variation in nutritional composition of Kappaphycus alvarezii (Doty) Doty: An edible seaweed. J. Food Sci. Technol., 52(5), 2751-2760, https://doi.org/10.1007/s13197-014-1372-0.

42. Fang, J. et al. (2004). The chemical modification of a range of starches under aqueous reaction conditions. Carbohydr. Polym., 55(3), 283-289, https://doi.org/ 10.1016/j.carbpol.2003.10.003.

43. Chi, H. et al. (2008). Effect of acetylation on the properties of corn starch. Food Chem., 106(3), 923-928, https://doi.org/10.1016/j.foodchem.2007.07.002.

44. Shankar, S. \& Rhim, J. W. (2016). Preparation of nanocellulose from microcrystalline cellulose: The effect on the performance and properties of agar-based composite films. Carbohydr. Polym., 135, 18-26, https://doi.org/10.1016/j.carbpol. 2015.08.082.

45. Prachayawarakorn, J. \& Pomdage, W. (2014). Effect of carrageenan on properties of biodegradable thermoplastic cassava starch/low-density polyethylene composites reinforced by cotton fibers. Mater. Des., 61, 264-269, https://doi.org/ 10.1016/j.matdes.2014.04.051. 